\title{
1 Analysis of flow processes in fractured chalk under pumped and ambient conditions
}

2 A. P. Butler ${ }^{1}$, S. A. Mathias ${ }^{1}$, A. J. Gallagher ${ }^{2}$, D. W. Peach ${ }^{2}$, and A. T. Williams ${ }^{2}$

$3{ }^{1}$ Department of Civil and Environmental Engineering, Imperial College London, London

4 SW7 2AZ, UK

$5 \quad{ }^{2}$ British Geological Survey, Wallingford OX10 8BB, UK

6

$7 \quad$ Corresponding email address: simon.mathias@imperial.ac.uk

8

9 Key words: dilution test, flowmeter, fractured rocks, hydraulic testing, pumping test

11 Paper submitted to Hydrogeology Journal 29/04/2008

13 Abstract

This paper describes an integrated set of different measurements that has been used to study the behavior of groundwater in an observation well in a fractured rock formation, the UK Chalk, under pumped and ambient conditions. Under pumped conditions the response of the open borehole was relatively straightforward with flow mainly concentrated along four discrete flow horizons. Furthermore, excellent correspondence was observed between the three methods of borehole flow velocity measurement: impeller flowmeter, heat-pulse flowmeter and dilution testing. Under ambient conditions the system appeared more complicated. Specifically, in the upper half of the borehole the impeller flowmeter exhibited substantial downward flow, the heat-pulse flowmeter exhibited almost negligible upward flow whilst dilution testing indicated significant dilution. It was concluded that this was due to cross-flow occurring over the upper $29 \mathrm{~m}$. Analysis of drawdown data, recovery data and a Drost analysis of the ambient cross-flow data yielded aquifer transmissivity estimates of $2049 \mathrm{~m}^{2} \mathrm{~d}^{-1}, 2928 \mathrm{~m}^{2} \mathrm{~d}^{-1}$ and $>4388 \mathrm{~m}^{2} \mathrm{~d}^{-1}$ respectively. The discrepancy between the drawdown and recovery estimates was attributed to non-linear head-losses associated with turbulence and inertial effects. The difference between the pumping test and Drost results was explained by the flow during the pumping test bypassing this aforementioned $29 \mathrm{~m}$ region of rock. 
Chalk aquifers represent some of the most important groundwater resources in the UK.

Consequently, great effort is incurred in developing catchment scale groundwater models of key water resources sites (see ENTEC, 2003 and references therein). These models routinely use parameters obtained from pumping test analysis (MacDonald and Allen, 2001). However, it is often found that when attempting to simulate the observed ambient (i.e. unpumped) groundwater response, a level of calibration is required (ENTEC, 2003; Rushton et al., 1989). This adjustment of parameter values is due to a range of problems including measurement error and model uncertainty (Liu and Gupta, 2007). However, another problem, not often discussed, is the extent that aquifer parameters derived under locally perturbed (i.e. pumped) conditions are suitable for applying to models that represent the system in the ambient state.

As part of the UK Natural Environment Research Council (NERC) thematic programme on LOwland CAtchment Research (LOCAR) (Wheater and Peach, 2004) three $100 \mathrm{~m}$ deep observation boreholes (PL10A, PL10B, PL10E) were placed around an Environment Agency river augmentation abstraction well at Bottom Barn (BBA) situated in the Berkshire Chalk aquifer, UK (see Figure 1 and Williams et al., 2006). Effort was focused on the characterization of PL10A, which benefited from extensive geophysical logging (caliper, gamma, temperature, televiewer etc.), packer testing, flow logging (using impeller and heatpulse flow meters) and dilution testing. Of particular interest is that temperature logging, flow logging and dilution testing were undertaken under ambient conditions and again when the BBA (situated $32 \mathrm{~m}$ away) was pumping at $5770 \mathrm{~m}^{3} \mathrm{~d}^{-1}$. In what follows it is shown that the pumping of BBA fundamentally changed the observed flow processes within PL10A raising a serious question concerning the application of results obtained from pumping tests in fractured rock aquifers such as the Chalk.

\section{Lithostratigraphy}

Traditionally, the Berkshire Chalk outcrop has been subdivided into the Upper, Middle and Lower Chalk formations (White, 1907). At a meeting of the Geological Society Stratigraphy Commission at the British Geological Survey (BGS) in 1999, a broadly agreed revised Chalk Group stratigraphy was adopted (Rawson et al., 2001), which was based on the more sophisticated lithostratigraphical classification applied by Mortimore (1986) and Robinson 
(1986). One of the useful markers for applying the new lithostratigraphical classification is a three-metre band, near the base of the Lewes Nodular Chalk (the base of the former Upper Chalk), known as the Chalk Rock (Schurch and Buckley, 2002; Woods and Adiss, 2004). This is because the phosphatized and glauconitized chalk pebble intraclasts, particularly common in the Chalk Rock, give rise to a significant increase in gamma-ray activity (Schurch and Buckley, 2002). Figure 2b shows a gamma-ray log of borehole PL10A where such a gamma-ray peak is present at $27 \mathrm{mAOD}$.

Following Schurch and Buckley (2002) and Woods and Adiss (2004), the Lewes Nodular Chalk formation was assumed to be around $20 \mathrm{~m}$ thick with its base located at the very bottom of the Chalk Rock gamma-ray perturbation. Therefore, the uncased section of borehole PL10A can be assumed to lie in around $10 \mathrm{~m}$ of New Pit Chalk, overlain by $20 \mathrm{~m}$ of Lewes Nodular Chalk, overlain by $50 \mathrm{~m}$ of Seaford Chalk (see Figure 2 for schematic). The New Pit formation is a firm, smooth-textured marly chalk while the Lewes Nodular is a hard, nodular, gritty chalk, with common flints, marl seams and hardgrounds. The base of the Seaford formation is at the upward change from hard, nodular, gritty chalk to soft, smoothtextured chalk (Woods and Adiss, 2004).

\section{Fractures}

To better visualize the physical structure of the aquifer at PL10A, an optical televiewer (OTV) log was obtained. The OTV log provides a 360 degree bitmap image of the entire borehole. Perfectly, planar sub-horizontal features manifest themselves as sine waves, from which the elevation, strike and dip of the fractures that intersect the borehole can be obtained (Paillet and Pedler, 1996). Theoretically, OTV logs can be interpreted automatically using techniques such as the Hough transform (Glossop et al., 1999). However, this requires that the OTV log is still intelligible after translating to a binary image. For the PL10A OTV log, this was not the case. Consequently, a manual technique was adopted. Ideally, this should be a simple case of locating the minimum and maximum points of the intersecting fractures' sine waves. However, for many of the fractures, the absolute location of the peaks and troughs was not clear. Therefore, a MATLAB program was developed to aid a more robust analysis (see Appendix). Figure 2c shows a tadpole plot of borehole PL10A derived from the OTV log. The tadpole body indicates the dip angle and the tail indicates the strike angle (or dip 
direction) (Williams and Paillet, 2002). It can be seen that there are many sub-horizontal fractures throughout the extent of the borehole.

\section{Packer testing}

The vertical distribution of hydraulic conductivity was measured using a constant head double-packer permeameter. The double-packer permeameter used in borehole PL10A incorporates a pump, to abstract water from the isolated section, and a transducer to measure the pressure within the section (see Price and Williams, 1993 for more detail). Once the section to be tested is isolated by inflating the packers, water is pumped out of the isolated interval at a constant rate, $Q\left[\mathrm{~L}^{3} \mathrm{~T}^{-1}\right]$. The head in the section is monitored using the transducer and pumping continues until a steady-state drawdown is measured, $\phi_{0}[\mathrm{~L}]$. In typical UK Chalk boreholes this takes around 20 minutes. The horizontal hydraulic conductivity of the tested section, $K\left[\mathrm{LT}^{-1}\right]$ is then calculated using (Hvorslev, 1951) $K=Q F / \phi_{0}$ where $F[\mathrm{~L}]$ is a shape factor dependant on the ratio of horizontal and vertical hydraulic conductivity and the geometry of the packered abstraction system. The appropriate shape factor for the double packer permeameter is given in the form of a simple polynomial approximation by Mathias and Butler (2007). Assuming an isotropic medium, the resulting hydraulic conductivity profile in Figure $2 \mathrm{~d}$ is obtained. It can be seen that the hydraulic conductivity values span almost five orders of magnitude. Generally there is a linear-log trend with elevation combined with around an order of magnitude of fluctuation. The profile is similar to those obtained at a number of other Chalk boreholes in the UK (Price et al., 1982; Price and Williams, 1993; Allen et al., 1997) and Israel (Nativ et al., 2003).

\section{Pumping test analysis}

As previously stated, the abstraction well, BBA was pumped at $5770 \mathrm{~m}^{3} \mathrm{~d}^{-1}$ for just over a day. Drawdown and recovery (after the cessation of pumping) were continuously monitored using minitrolls in the three observation boreholes and the abstraction well (Figure 3). Following the recommendation of Meier (1998), estimates of effective transmissivities were obtained using Jacob's straight line method on the late time data. Note that recovery data is plotted on a transformed axis (Agarwal, 1980; Samani and Pasandi, 2003) such that it can also be analysed using Jacob's method. The resulting transmissivity estimates are given in 
133 Table 1. The mean transmissivity calculated to be $2049 \pm 230 \mathrm{~m}^{2} \mathrm{~d}^{-1}$ from the drawdown

134 phase results and $2928 \pm 229 \mathrm{~m}^{2} \mathrm{~d}^{-1}$ from the recovery. These are well within the national 135 ranges for the Chalk (MacDonald and Allen, 2001), further supporting that this is a relatively 136 typical site.

138 The discrepancy between the drawdown and recovery transmissivities is a common 139 occurrence although rarely addressed. Rushton and Chan (1976) showed that the discrepancy 140 between drawdown and recovery data could sometimes be explained by vertical variations in 141 hydraulic conductivity. Rushton and Booth (1976) and Shapiro et al. (1998) suggest that the 142 discrepancy can also be due to non-linear head losses within the well-bore. However, the idea 143 that non-linear head losses only occur within the well-bore is a common misconception dating back to the empirical work of Jacob (1946). In fact, non-linear head losses due to turbulence, microscopic inertia and microscopic drag (Giorgi, 1997) are likely to occur over a large region within the aquifer around the well-bore due to the fast velocities caused by the convergence of flow-lines (Kohl et al., 1997). This is likely to be particularly important in

148 Chalk aquifers where groundwater flow in the saturated zone is often largely confined to a 149 limited number of well connected flow pathways (e.g. Mathias et al., 2007, Hartmann et al., 150 2007).

\section{Flow logging}

154 To gain information about which portions of the aquifer are likely to be contributing to this transmissivity, upflow logs were obtained using both impeller and heat-pulse flowmeters.

Impeller flowmeter measurement involves lowering an impeller down a borehole at a fixed rate and logging the rotation rate of the impeller. The net upflow velocity is obtained from a simple calibration equation, which in turn can be converted to an estimated flow rate by multiplying by the borehole cross-sectional area obtained from caliper log measurements.

161 Note therefore that noise in the flow impeller profiles is partially due to error in the borehole area measurement. The main shortcoming of impeller flowmeters is their lack of sensitivity to low-velocity flow For smaller flow rates, a heat-pulse flowmeter is more appropriate. 
165 The heat-pulse flowmeter was originally developed by Dudgeon et al. (1975). An electrical heating grid, located between two thermistors, is heated by a short pulse of electrical current. The heated lens of water is moved towards one of the thermistors by the vertical component of flow in the borehole. The arrival time of the heat-pulse at the thermistor is recorded. If the heat-pulse is detected by the upper one, flow is upwards and vice versa. The flow velocity can then be calculated by dividing the distance between the element and thermistor by the respective travel time. Again, the flow-rate is estimated by multiplying the velocity by the local cross-sectional area from the caliper log. Note that neither the impeller nor heat-pulse flowmeters used in this study were capable of measuring flow across the borehole. The direct measurement of cross-flow requires more sophisticated instrumentation (e.g. James et al., 2006; Su et al., 2006).

Figures 4a and 5a show measured upflow profiles for borehole PL10A whilst pumping BBA and under ambient conditions respectively. As the results obtained during pumping are more straightforward to interpret, these are discussed first. It can be observed that there is relatively good correspondence between the impeller and heat-pulse flowmeters. The step changes in the impeller log are indicative of discrete flow horizons. It is apparent that there is an upflow at the base of the borehole, followed by an additional inflow at $27 \mathrm{mAOD}$, which corresponds to the Chalk Rock (compare Figure 2b). There is a small outflow at $57 \mathrm{mAOD}$ followed by a much larger outflow at $74 \mathrm{mAOD}$, which is sufficient to change the flow direction. Finally, the impeller and heat-pulse logs suggest that there is an inflow in the vicinity of the water table. This description is further supported by the temperature log in Figure $4 b$, where inflections can be seen at $27 \mathrm{mAOD}$ and $74 \mathrm{mAOD}$.

Under ambient conditions, the picture is more complicated. First, flow rates are generally around a quarter of those for the pumped condition. Second, the impeller flowmeter log in

191 Figure 5a shows an upflow from the base of the hole and an outflow at 57 mAOD that appears to change the flow direction such that there is a substantial downward flow in the upper part of the borehole (the large peak at $63 \mathrm{mAOD}$ is probably due to the flowmeter hitting the side of the borehole). From 57mAOD to 85mAOD the impeller flowmeter results are very variable and always negative. This could be indicative of some downward movement or cross-flow. The temperature log indicates a steep gradient from $57 \mathrm{~m}$ to 74 , confirming very low flows in this interval, but it has a zero gradient above $74 \mathrm{mAOD}$ suggesting downward movement perhaps exiting the borehole at 74mAOD. Between 57 and 74 there are 
only two heat pulse measurements, one positive and similar to those at greater depth, and one of zero at $65 \mathrm{~m}$. The higher heat pulse measurements (measuring zero) are found in the region above $74 \mathrm{~m}$. It seems likely that the disagreement in these various results is indicative of low vertical flows but significant cross-flow The distribution of the cross-flow is impossible to estimate but seems likely to be highest at $74 \mathrm{mAOD}$ or just above this point, with less significant flow between 57mOAD and 74mAOD.

\section{Flow processes within the abstraction well}

Unfortunately, the pump broke down before the logging team had time to carry out geophysical logging in the abstraction well (BBA). Consequently, it was restarted five days later at a reduced rate of $4750 \mathrm{~m}^{3} \mathrm{~d}^{-1}$. The rate reduction was required for operational reasons and was unfortunate as it made direct comparison with the results from PL10A more problematic. Nevertheless, Figure 6 shows gamma, temperature, fluid electrical conductivity (FEC) and impeller flowmeter logging under pumped and ambient conditions. The gamma

$214 \log$ indicates the elevation of the Chalk Rock horizon to be a little higher at 28 mAOD than 215 found in PL10A. The temperature $\log$ is relatively flat although there is evidence of warming 216 at $23.6 \mathrm{mAOD}$ where the pump is located. Under ambient conditions, the FEC log shows a 217 distinct step change at $45 \mathrm{mAOD}$, which is replaced under pumped conditions by three 218 separate changes at $48 \mathrm{mAOD}, 61 \mathrm{mAOD}$ and $82 \mathrm{mAOD}$. These changes are likely to mark the main flowing horizons.

Figure $6 \mathrm{~d}$ shows impeller flowmeter data. Under ambient conditions, flow rates are comparable with those observed in PL10A. Under pumped conditions, it appears that $2,000 \mathrm{~m}^{3} \mathrm{~d}^{-1}$ enters the borehole between $82 \mathrm{mAOD}$ and $79 \mathrm{mAOD}$, below which there is a steady increase in down-flow to $61 \mathrm{mAOD}$. At this point a flow of approximately $3600 \mathrm{~m}^{3} \mathrm{~d}^{-1}$ is achieved which is increased to $4750 \mathrm{~m}^{3} \mathrm{~d}^{-1}$ by $48 \mathrm{mAOD}$. There is considerable uncertainty over this interpretation because the variability in borehole diameter is unknown. Nevertheless, the significant fluctuations about clear trends are believed to be largely due to borehole diameter variability. A caliper log was not available so a constant borehole diameter of $0.762 \mathrm{~m}$ was assumed (based on the original completion report). However, as the abstraction borehole was acidized during development to increase the yield (Harker, 1974), it would be reasonable to assume that variations in diameter were accentuated and that active fractures were opened significantly by this process. The acidization process would have 
233 depressed the water table considerably and pushed the acid well into the Chalk along open

234 fractures, increasing the permeability greatly.

\section{Dilution testing}

238 Dilution tests were also performed to complement the logged flow data from PL10A (see 239 Figures $4 \mathrm{c}$ and 5c). These involve lowering a fluid electrical conductivity (FEC) probe down 240 the borehole to obtain a measure of background conductivity with depth. A tube is then lowered down to the base of the borehole and filled with a well-mixed saline solution. The tube is then retrieved so as to provide a close to uniform, elevated FEC along the borehole. As water enters and leaves the borehole via natural flow horizons the saline solution is diluted. The rate of dilution is then monitored by subsequent FEC logging. The result is a series of FEC profiles for a range of different times.

Dilution test data can be inverted to acquire flow rates associated with discrete flow horizons using a dilution test model. Such models generally assume steady-state flow and that the borehole is fully mixed laterally. In this way, solute concentrations within the borehole can be described by a one-dimensional advection dispersion equation subjected to discrete sources and sinks associated with flowing horizons (Tsang et al. 1990).

Most studies have looked at dilution test model inversions for pumped wells (Tsang et al. 1990; Tsang and Doughty, 2003; Evans 1995; Karasaki et al., 2000; Doughty, 2005). This is generally straightforward; providing the pumping rate is large enough, only inflowing features are present. These can be easily located at the beginning of the test as discrete dilution features. However, when the borehole is not directly pumped (as is the case for both ambient and pumped conditions in this paper) the presence of outflowing horizons is likely. Unfortunately, outflow locations are not apparent until later on in the test, by which time the conductivity profiles are generally complex due to the interactions different features (Doughty 2005). Therefore, outflow horizons, and consequently non-pumped wells, are much harder to interpret (Michalski and Klepp, 1990; Williams et al. 2006; Mathias et al., 2007). 
266 Note that the pumped condition did not involve pumping PL10A, but a neighboring abstraction well $35 \mathrm{~m}$ away (BBA). Nevertheless, from the analysis of the flowmeter and temperature data, inflows appear to occur at $10 \mathrm{mAOD}$ and $27 \mathrm{mAOD}$, and outflows at $57 \mathrm{mAOD}$ and $74 \mathrm{mAOD}$. By inspection of the dilution test data, an additional inflow probably exists at $79 \mathrm{mAOD}$. Using a model similar to that of Tsang et al. (1990), Mathias et al. (2007) obtained the set of calibrated inflows and outflows listed in the flow chart to the right of the dilution test data (Figure 4c). The comparison between the resulting simulated and observed upflow and salt concentration data is very convincing (see Figures $4 \mathrm{a}$ and c).

From these results it is clear that water table observations made in PL10A whilst pumping do not necessarily reflect the overall aquifer response. Rather, they represent the integrated response of the four discrete flow horizons and the upflow from the base of the borehole.

Ambient conditions

The dilution test performed under ambient conditions is much harder to interpret (Figure $5 \mathrm{c}$ ). There is definitely an upflow from the base most of which leaves the borehole at $57 \mathrm{mAOD}$. The difficulty arises in the upper region of the borehole (> $57 \mathrm{mAOD})$. At a glance, it appears that there are two major inflows at $74 \mathrm{mAOD}$ and $79 \mathrm{mAOD}$, which push the salt down to the outflow at $57 \mathrm{mAOD}$. However, this conflicts with the heat-pulse flowmeter and temperature data (compare Figures 5a and $\mathrm{b}$ ), which suggest that there is very low vertical flow in this region. Furthermore, although salt arising from the bottom of the hole initially looks as though it does not pass the $57 \mathrm{mAOD}$ horizon, the final profile recorded after $587 \mathrm{~min}$ shows some passing (subsequent testing has shown that this feature is repeatable). This implies that the vertical flow above $57 \mathrm{mAOD}$ is very small in an upward direction, this is confirmed by the heat pulse measurement at $59 \mathrm{mAOD}$, but which is in complete contrast to the impeller flowmeter data. Therefore, it is assumed that the dilution taking place in the upper region is due to a complex distribution of cross-flow, which is not measured by the impeller or heatpulse flowmeters.

Due to the number of degrees of freedom, it is difficult to delineate the vertical distribution of cross-flow using the aforementioned dilution test model. However, an estimate of the total cross-flow, $Q_{c}\left[\mathrm{~L}^{3} \mathrm{~T}^{-1}\right]$ in that region can be obtained using the analytical solution of Drost et al. (1968) 


$$
\frac{\bar{c}-\bar{c}_{0}}{\bar{c}_{i}-\bar{c}_{0}}=\exp \left(-\frac{V t}{Q_{c}}\right)
$$

302

where $\bar{c}\left[\mathrm{ML}^{-3}\right], \bar{c}_{0}\left[\mathrm{ML}^{-3}\right]$ and $\bar{c}_{i}\left[\mathrm{ML}^{-3}\right]$ are the mean current, mean background and mean initial salt concentrations respectively, $V\left[\mathrm{~L}^{3}\right]$ is volume of borehole under consideration and $t$ $[\mathrm{T}]$ is time after tracer injection.

307 Figure 7 shows a plot of mean concentration against time in borehole PL10A for $308 z>57$ mAOD under ambient conditions. Interestingly it does not converge on to the mean 309 background value, $\bar{c}_{0}$ during the time studied. This is because salt is moving up (albeit at a 310 very slow rate) past the 57 mAOD horizon. Therefore, when fitting the Drost et al. (1968)

311 formula, the $\bar{c}_{0}$ parameter should be considered unknown.

313 If $\bar{c}_{0}$ and $\bar{c}_{i}$ are known, equation (1) can be fitted to the data using linear regression (by applying a $\log _{\mathrm{e}}$ transformation to the concentration data). However, because this is not the case, a non-linear method is required. Specifically, the RMSE (root mean squared error)

$$
\mathrm{RMSE}=\sqrt{\frac{1}{N} \sum_{n=1}^{N}\left(\bar{c}_{n}-\bar{c}_{o b s, n}\right)^{2}}
$$

was minimized using a simplex search method available with MATLAB called FMINSEARCH. $N$ [-] is the number of data samples, $\bar{c}_{n}\left[\mathrm{ML}^{-3}\right]$ and $\bar{c}_{o b s, n}\left[\mathrm{ML}^{-3}\right]$ are the $n^{\text {th }}$ modelled and observed concentration values.

A plot of the calibrated curve alongside the data is shown in Figure 6 . The final parameter and RMSE values were $Q_{c} / V=0.015 \mathrm{~min}^{-1}, \bar{c}_{0}=0.48 \mathrm{~kg} \mathrm{~m}^{-3}$ and RMSE $=0.02 \mathrm{~kg} \mathrm{~m}^{-3}$. The $\bar{c}_{i}$ was estimated by averaging the 2 to 8 minutes profile. From the calliper log, the volume of this portion of the borehole was calculated to be $V=0.97 \mathrm{~m}^{3}$. Therefore, the estimated value of total cross-flow was found to be $Q_{c}=22 \mathrm{~m}^{3} \mathrm{~d}^{-1}$. 
331 The above calculated value of cross-flow, in conjunction with the local hydraulic gradient, can be used to calculate an additional estimate of aquifer transmissivity that is independent of the perturbation caused by pumping BBA. From the water level elevations in PL10A, PL10B and PL10E prior to pumping BBA, the local hydraulic gradient, $J_{x}[-]$ was estimated to be $1 /(224 \pm 53)$ (error is based on $0.5 \mathrm{~cm}$ error on water level elevations). An estimate of the regional groundwater flow, $q\left[\mathrm{~L}^{3} \mathrm{~T}^{-1} \mathrm{~L}^{-1}\right]$ can be obtained from $q=Q_{c} /(\alpha D)$ where $D[\mathrm{~L}]$ is the borehole diameter and $\alpha[-]$ is a dimensionless borehole factor. Assuming that the well is perfectly circular and the aquifer is isotropic and homogenous, Bidaux and Tsang (1991) calculated that $\alpha=2$. From the caliper $\log$ (Figure 2a) the average diameter of PL10A over the region $57 \mathrm{mAOD}<z<86 \mathrm{mAOD}$ was $0.206 \mathrm{~m}$. It follows that an estimate of the regional groundwater flow around PL10A is $22 /(2 \times 0.206)=53.4 \mathrm{~m}^{3} \mathrm{~d}^{-1} \mathrm{~m}^{-1}$. Applying Darcy's Law then leads to a transmissivity estimate of $11,945 \pm 974 \mathrm{~m}^{2} \mathrm{~d}^{-1}$, an order of magnitude larger than the values obtained from the pumping test analysis (in Figure 3) and outside the national statistical distributions presented by MacDonald and Allen (2001). However, for a well developed borehole Bidaux and Tsang (1991) suggest that $\alpha$ might be more around 5, which leads to a more realistic transmissivity value of $4778 \pm 390 \mathrm{~m}^{2} \mathrm{~d}^{-1}$.

Given the difference in flow distributions in PL10A under pumped and ambient conditions, the discrepancy in transmissivity estimates is not surprising. Under pumped conditions, flow was concentrated in just four discrete horizons where as under ambient conditions flow appeared to be distributed over a region of around $29 \mathrm{~m}$ thickness, but it seems likely that most cross-flow occurs above 79mAOD. However, if this was really the case, it is expected that the integrated value of the packer test results should also be of the order $5000 \mathrm{~m}^{2} \mathrm{~d}^{-1}$. The packer test data in Figure $2 \mathrm{~d}$ would therefore suggest that there must be features above those measured of significantly greater permeability. Unfortunately it was not possible to observe these as the borehole at this elevation was too wide for the packers.

\section{Conclusions}

This integrated study has revealed significant new insights into the behavior of groundwater flow and head in an observation and abstraction borehole in the UK fractured Chalk aquifer 
363 relatively straightforward manner flow being mainly concentrated in four discrete flow

364 horizons. Furthermore, excellent correspondence was observed between the three methods of borehole flow velocity measurement: impeller flowmeter, heat-pulse flowmeter and dilution test inversion. Under ambient conditions the system appears much more complicated. Specifically, in the upper half of the borehole the impeller flowmeter suggested a substantial downward flow, the heat-pulse flowmeter suggested a close to negligible upward flow whilst the dilution testing provided evidence of significant dilution. It was concluded that this was due to the significant cross-flow occurring over a region of $29 \mathrm{~m}$ thickness. Analysis of drawdown data, recovery data and a Drost analysis of the ambient crossflow data yielded aquifer transmissivity estimates of $2049 \mathrm{~m}^{2} \mathrm{~d}^{-1}, 2928 \mathrm{~m}^{2} \mathrm{~d}^{-1}$ and $>4388 \mathrm{~m}^{2} \mathrm{~d}^{-1}$ respectively. The discrepancy between the drawdown and recovery estimates is assumed to be caused by non-linear head-losses associated with turbulence and inertial effects. The difference between the pumping test and Drost results was then explained by the groundwater flow during pumping bypassing this aforementioned $29 \mathrm{~m}$ region of aquifer.

378 Changes in observation well flow profiles induced by pumping in another well are primarily thought to occur due to changes in the head distribution of the large-scale flowpaths (Le Borgne et al., 2006). Previously, this phenomenon has been exploited to identify and characterize those features that are directly connected to the abstraction well (Williams and Paillet. 2002; Le Borgne et al., 2006). However, in many instances, aquifer parameters are sought for modeling groundwater or catchment behavior away from the presence of abstraction wells. These might, for example, be to evaluate water resources, minimum environmental stream flows or responses to extreme events (droughts and floods), This emphasises the great care that must be taken in the extrapolation of pumping test results to ambient flow conditions. The marked change in flow pathways also implies that similar caution is required when applying transport parameters obtained during pumping to such conditions.

\section{Appendix - Details of the strike and dip program}

A fracture is identified from a visual inspection of the OTV bitmap image. The user then selects three points anywhere along the fracture intersect: $\left(\theta_{1}, z_{1}\right),\left(\theta_{2}, z_{2}\right)$ and $\left(\theta_{3}, z_{3}\right)$, where $0<\theta<2 \pi$ (i.e. North $=0$ and South $=\pi$ ) and $z$ [L] is elevation. The program then superimposes the sine wave 


$$
z=\Delta z \sin (\theta+\alpha)+z_{0}
$$

399

400 where

401

402

403

404

$$
\Delta z=a \sec (\alpha)
$$

$\tan (\alpha)=-b / a$

405

406

and

407

408

409

$$
z_{0}=\frac{z_{3} \sin \left(\theta_{1}-\theta_{2}\right)+z_{2} \sin \left(\theta_{3}-\theta_{1}\right)+z_{1} \sin \left(\theta_{2}-\theta_{3}\right)}{\sin \left(\theta_{1}-\theta_{2}\right)+\sin \left(\theta_{3}-\theta_{1}\right)+\sin \left(\theta_{2}-\theta_{3}\right)}
$$

410

411 The three points can then be moved independently, and the sine wave automatically corrects

412 itself to fit them. The user can keep moving the points until an appropriate visual fit between

413 the sine wave and the fracture intersect is achieved (see Figure 8). The final values of $\left(\theta_{1}, z_{1}\right)$, $414\left(\theta_{2}, z_{2}\right)$ and $\left(\theta_{3}, z_{3}\right)$ are subsequently stored. The strike and dip of the fracture can then be 415 obtained from

416

417

$$
\text { strike }= \begin{cases}\pi / 2-\alpha, & \Delta z<0 \\ 3 \pi / 2-\alpha, & \Delta z \geq 0\end{cases}
$$

418

$$
\operatorname{dip}=\arctan (2|\Delta z| / D)
$$

419

420

\section{References}

421

Agarwal RG (1980) A new method to account for producing time effects when drawdown type curves are used to analyze pressure buildup and other test data. SPE Paper 9289 presented at the 55th SPE Annual Technical Conference and Exhibition, 21-24 
Allen DJ, Brewerton LJ, Coleby LM, Gibbs BR, Lewis MA, MacDonald AM, Wagstaff SJ, Williams AT (1997) The Physical Properties of Major Aquifers in England and Wales. British Geological Survey Technical Report, WD/97/34

Bidaux P, Tsang CF (1991) Fluid flow patterns around a well bore or an underground drift with complex skin effects. Water Resour Res 27(11): 2993-3008

Doughty C (2005) Signatures in flowing fluid electric conductivity logs. J Hydrol 310: 157180

Drost W, Klotz D, Koch A, Moser H, Neumaier F, Rauert W (1968) Point dilution methods of investigating ground water flow by means of radioisotopes. Water Resour Res 4(1): $125-146$

Dudgeon CR, Green MJ, Smedmor WJ (1975) Heat-pulse flowmeter for boreholes: Medmenham. Technical Report TR4., Water Research Centre, England

ENTEC (2005) A Comparison of Chalk Groundwater Models in and Around the River Test Catchment. Report PP-925

Evans DG (1995) Inverting fluid conductivity logs for fracture inflow parameters. Water Resour Res 31(12): 2905-2916

Giorgi T (1997) Derivation of the Forchheimer law via matched asymptotic expansions. Transp Porous Media 29(2): 191-206

Glossop K, Lisboa PJG, Russel PC, Siddans A, Jones GR (1999) An implementation of the Hough transformation for the identification and labelling of fixed period sinusoidal curves, Computer Vision and Image Understanding 74(1): 96-100

Harker D (1974) Groundwater scheme stage 1: Pumping test at Bottom Barn SU57/151. Ground Water Section, TCD, Thames Water Authority

Hartmann S, Odling NE, West LJ (2007) A multi-directional tracer test in the fractured Chalk aquifer of E. Yorkshire, UK. J Contam Hydrol 94: 315-331

James SC, Jepsen RA, Beauheim RL, Pedler WH, Mandell WA (2006) Simulations to verify horizontal flow measurements from a borehole flowmeter. Ground Water 44(3): 394405

Keys SW (1990) Borehole geophysics applied to groundwater investigations. USGS Techniques of Water-Resources Investigations, Book 2, Chapter E2

Kohl T, Evans KF, Hopkirk RJ, Jung R, Rybach L (1997) Observation and simulation of nonDarcian flow transients in fractured rock. Water Resour Res 33(3): 407-418

Le Borgne T, Paillet F, Bour O, Caudal JP (2006) Cross-borehole flowmeter tests for transient heads in heterogeneous aquifers. Ground Water 44(3): 444-452 
460 Liu Y, Gupta HV (2007) Uncertainty in hydrologic modeling: Toward an integrated data assimilation framework. Water Resour Res 43: W07401

MacDonald AM, Allen DJ (2001) Aquifer properties of the Chalk of England. Q J Eng Geol 34: $371-384$

Mathias SA, Butler AP (2007) Shape factors for constant-head double packer permeameters. Water Resour Res 43: W06430

Mathias SA, Butler AP, Peach DW, Williams AT (2007) Recovering tracer test input functions from fluid electrical conductivity logging in fractured porous rocks. Water Resour Res 43: W07443

Meier PM, Carrera J, Sanchez-Vila X (1998) An evaluation of Jacob's method for the interpretation of pumping tests in heterogeneous formations. Water Resour Res 34(5): 1011-1025

Michalski A, Klepp GM (1990) Characterization of transmissive fractures by simple tracing of in-well flow. Ground Water 28(2): 191-198

Nativ R, Adar E, Assaf L, Nygaard E (2003) Characterization of the hydraulic properties of fractures in chalk. Ground Water 41(4): 532-543

Paillet FL, Pedler WH (1996) Integrated borehole logging methods for wellhead protection applications. Eng Geol 42: 155-165

Price M, Morris B, Robertson A (1982) A study of intergranular and fissure permeability in Chalk and Permian aquifers, using double-packer injection testing. J Hydrol 54: 401423

Price M, Williams AT (1993) A pumped double-packer system for use in aquifer evaluation and groundwater sampling. Proceedings of the Institution of Civil Engineers, Part 2, 101: 85-92

Rawson PF, Allen P, Gale AS (2001) The Chalk Group revised lithostratigraphy. Geoscientist 11:21

Rushton KR, Chan YK (1976) Pumping test analysis when parameters vary with depth. Ground Water 14: 82-87

Rushton KR, Booth SJ (1976) Pumping-test analysis using a discrete time-discrete space numerical method. J Hydrol 28: 13-27.

Rushton KR, Connorton BJ, Tomlinson LM (1989) Estimation of the ground water resources of the Berkshire Downs supported by mathematical modelling. Q J Eng Geol 22: 329341 
493

494

495

496

497

498

499

500

501

502

503

504

505

506

507

508

509

510

511

512

513

514

515

516

517

Samani N, Pasandi M (2003) A single recovery type curve from Theis' exact solution. Ground Water, 41(5): 602-607 [Notice of Plagiarism with regard to this paper appeared in Ground Water 42(1)]

Schurch M, Buckley D (2002) Integrating geophysical and hydrochemical borehole-log measurements to characterize the Chalk aquifer, Berkshire, United Kingdom. Hydrogeol J 10: 610-627

Shapiro AM., Oki DS, Green EA (1998) Estimating formation properties from early-time recovery in wells subject to turbulent head losses. J Hydrol 208: 223-236

Su GW, Freifeld BM, Oldenburg CM, Jordan PD, Daley PF (2006) Interpreting velocities from heat-based flow sensors by numerical simulation. Ground Water 44(3): 386-393

Tsang CF, Hufschmeid P, Hale FV (1990) Determination of fracture inflow parameters with a borehole fluid conductivity logging method. Water Resour Res 26(4): 561-578

Tsang CF, Doughty C (2003) Multirate flowing fluid electric conductivity logging method. Water Resour Res 39(12): 1354

Wheater HS, Peach DW (2004) Developing interdisciplinary science for integrated catchment management: The UK LOwland CAtchment Research (LOCAR) Programme. Int J Water Resour Dev 20: 369-385

White HJO (1907) The Geology of the Country around Hungerford and Newbury, Memoir, British Geological Survey

Williams JH, Paillet FL (2002) Using flowmeter pulse tests to define hydraulic connections in the subsurface: a fractured shale example. J Hydrol 265: 100-117

Williams A, Bloomfield J, Griffiths K, Butler A (2006) Characterising the vertical variations in aquifer properties within the Chalk aquifer. J Hydrol 330: 53-62

Woods MA, Aldiss DT (2004) The stratigraphy of the Chalk Group of the Berkshire Downs. Proceedings of the Geologists' Association 115: 249-265 
518 Table 1 Transmissivity data obtained from Jacob analysis (see Figure 3)

519

520 Borehole

Drawdown

Recovery

$521 \quad$ BBA

$1782 \mathrm{~m}^{2} /$ day

$2933 \mathrm{~m}^{2} /$ day

522 PL10A

$2328 \mathrm{~m}^{2} /$ day

$3076 \mathrm{~m}^{2} /$ day

523 PL10B

$2219 \mathrm{~m}^{2} /$ day

$3147 \mathrm{~m}^{2} /$ day

524 PL10E

$866 \mathrm{~m}^{2} /$ day $2555 \mathrm{~m}^{2} /$ day

525 Mean

$2049 \mathrm{~m}^{2} /$ day

$2928 \mathrm{~m}^{2} /$ day

526 Standard deviation

$230 \mathrm{~m}^{2} /$ day

$229 \mathrm{~m}^{2} /$ day

527

PL10B O

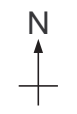

O PL10E

PL10A O $5.77 \mathrm{Ml} /$ day.

Figure 1 Site layout 

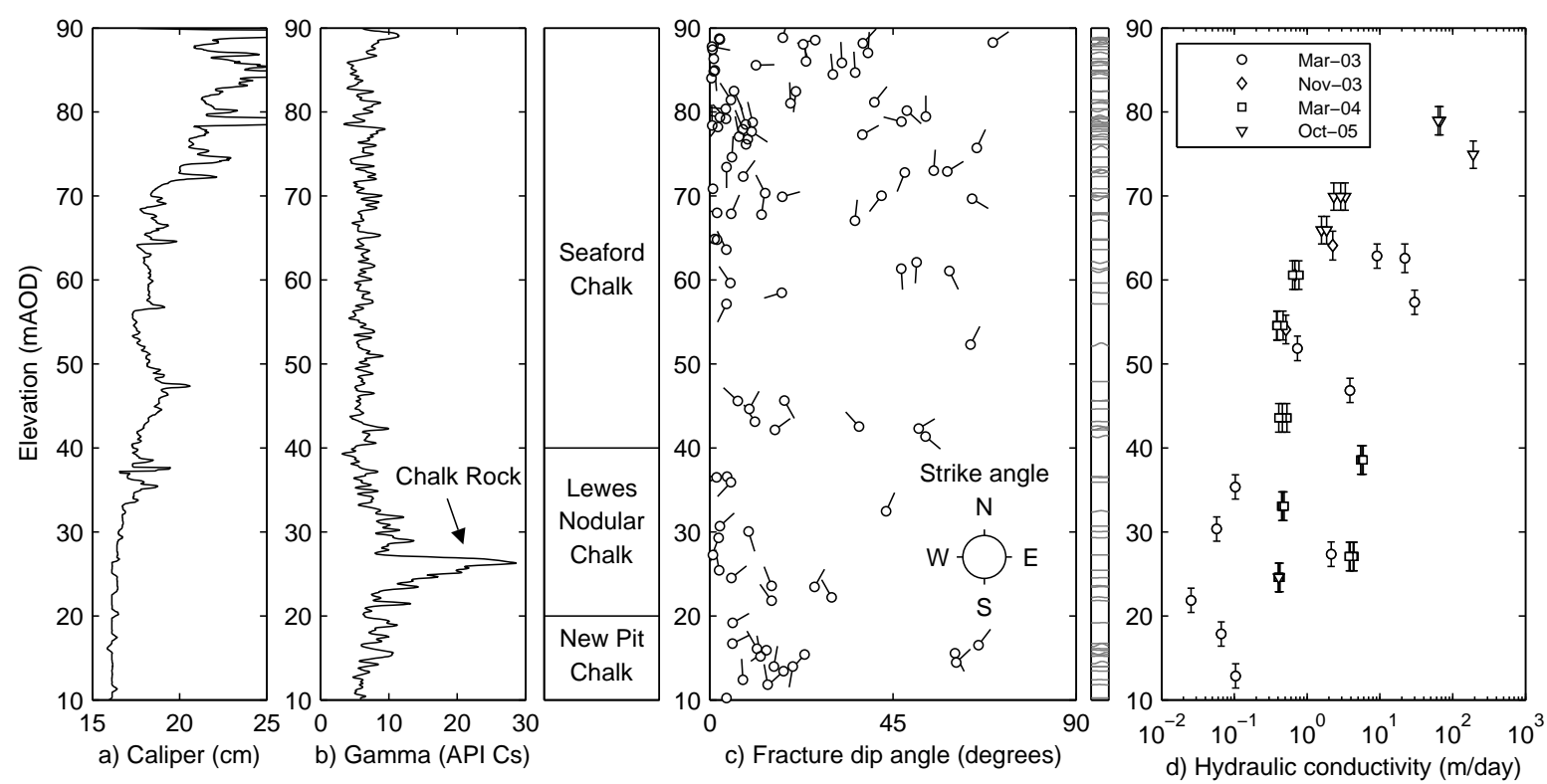

Figure 2 Stratigraphy, fracturing and hydraulic conductivity distributions for borehole

532 PL10A. Subplot (a) shows the variation of borehole diameter with elevation. Subplot (b)

533 shows a natural gamma log along with the stratigraphy inferred from it. Subplot (c) is a

534 tadpole plot, derived from the televiewer $\log$ (see sketch to the right), showing the dip 535 (tadpole body) and strike (tadpole tail) of the fractures. Subplot (d) shows the hydraulic 536 conductivity distribution measured from the constant head double packer permeameter tests.

537 These were taken at different dates as detailed in the legend. The error bars represent the 538 length of isolated interval $(\approx 3 \mathrm{~m})$. 
PL10B

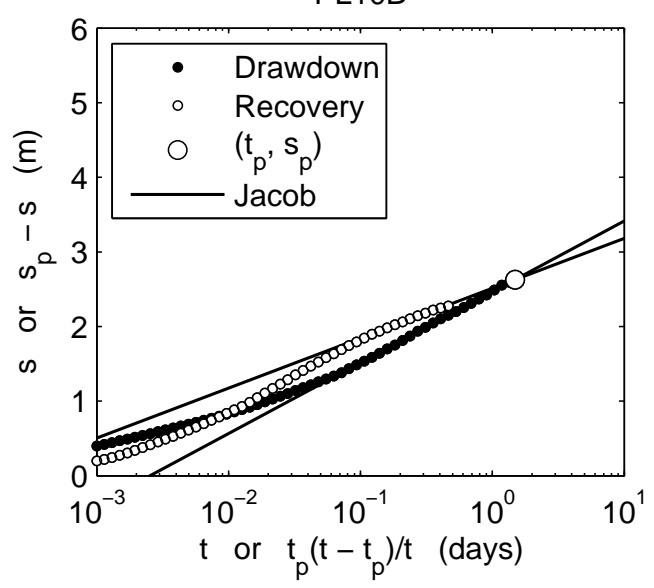

PL10A

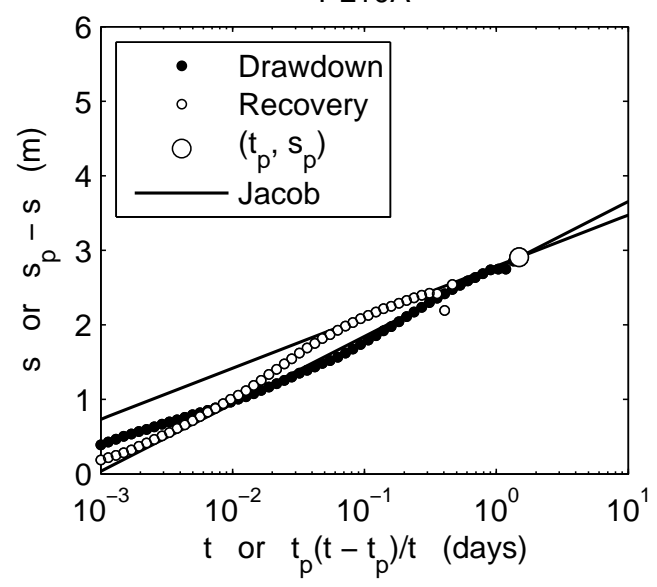

PL10E
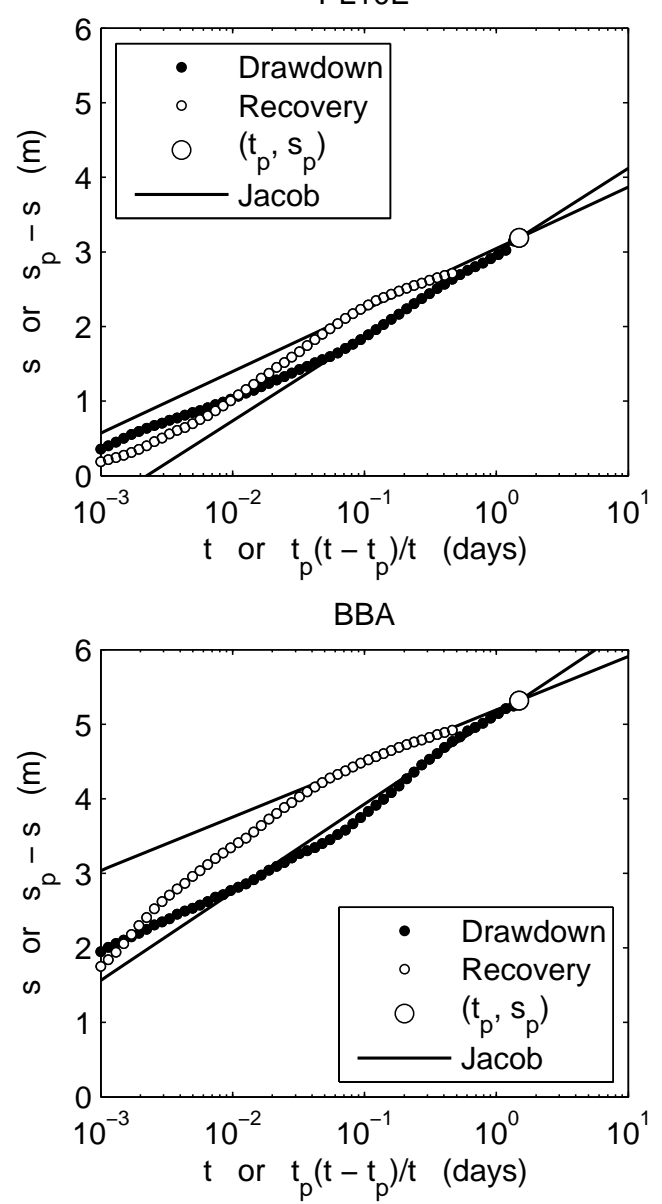

541 Figure 3 Plots of drawdown and recovery for BBA, PL10A, PL10B and PL10E whilst 542 pumping BBA at $5.77 \mathrm{Ml} /$ day. Note that $t_{p}$ and $s_{p}$ refers to the time the pump was switched 543 off and the corresponding drawdown. For drawdown $s$ is plotted against $t$ where as for 544 recovery $s_{p}-s$ is plotted against $t_{p}\left(t-t_{p}\right) / t$. 

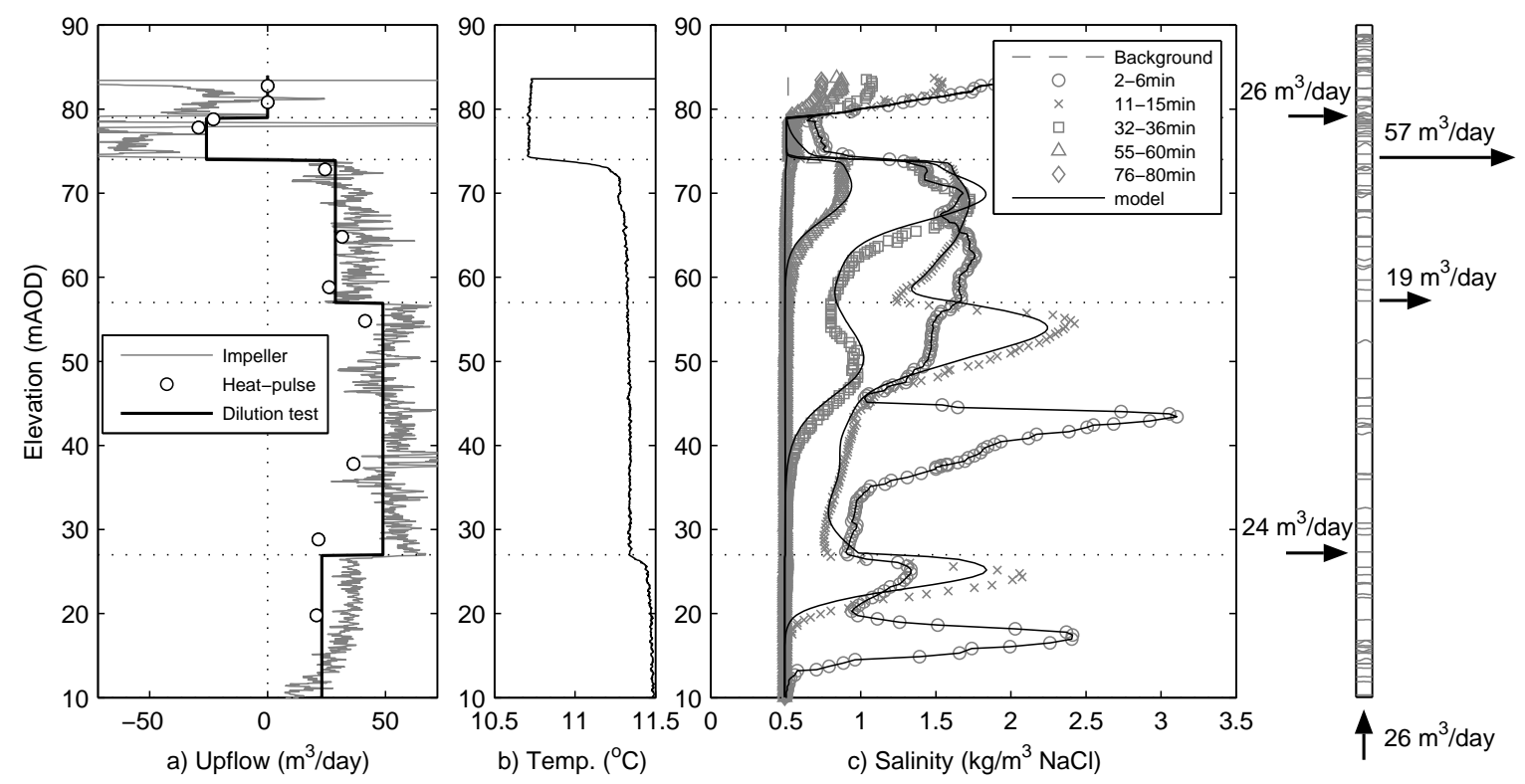

Figure 4 Flow logging, temperature logging and dilution testing in PL10A whilst pumping 548 the Bottom Barn abstraction well ( $\approx 35$ m away).

549
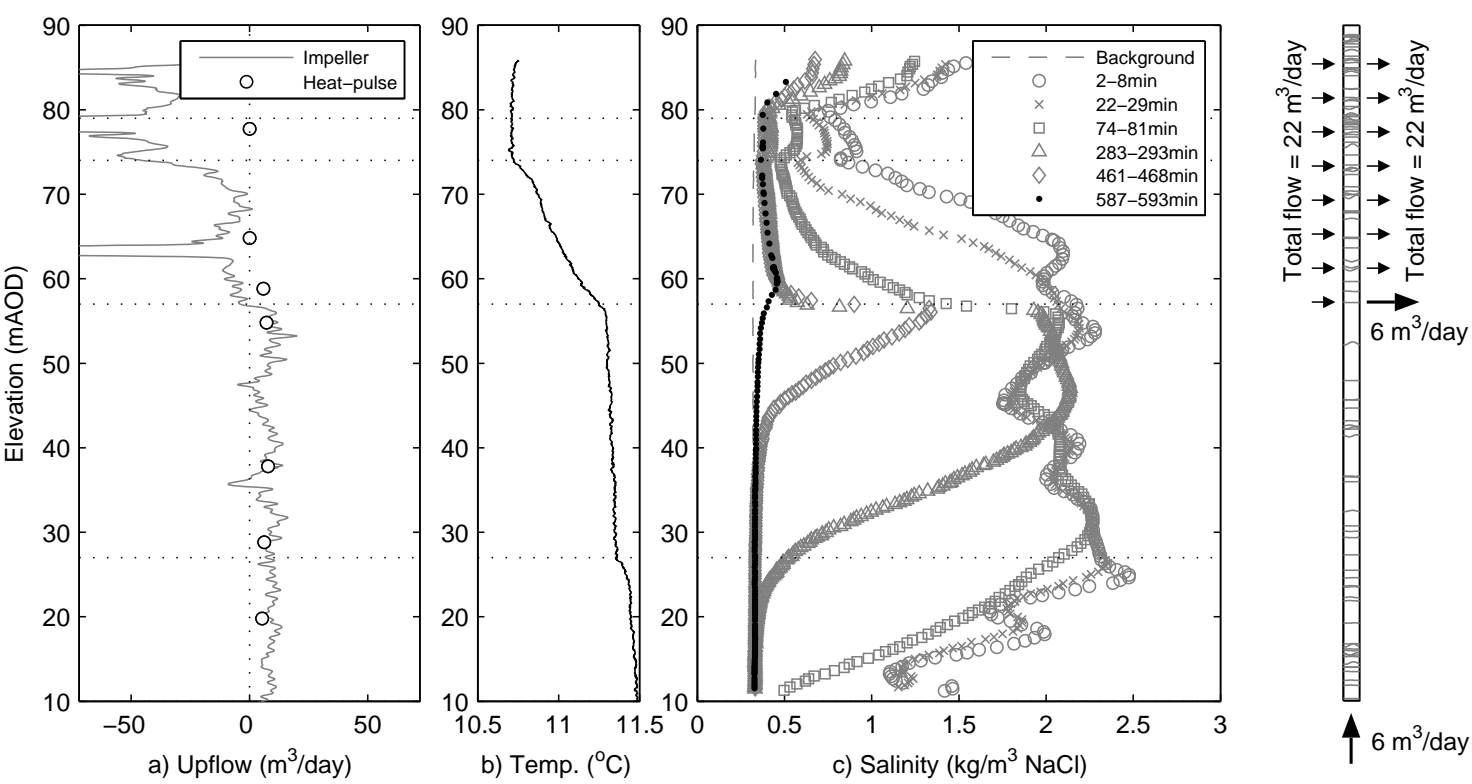

551 Figure 5 Flow logging, temperature logging and dilution testing in PL10A under ambient 552 conditions. 

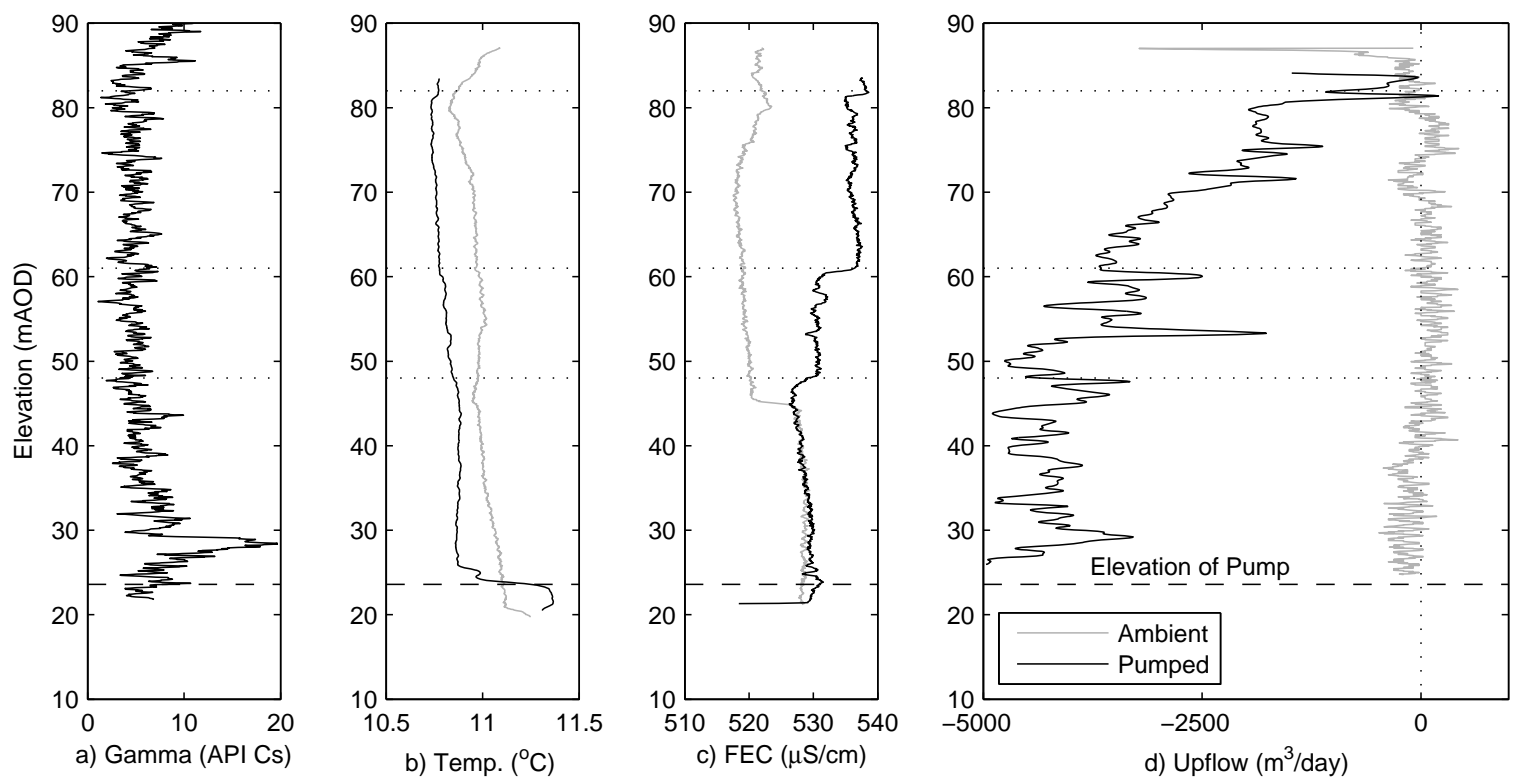

555 Figure 6 Gamma, temperature, fluid electrical conductivity and impeller flowmeter logging 556 in BBA. Note that this logging was undertaken 5 days after the previously discussed pumping 557 test and the BBA was pumped at a reduced rate of $4750 \mathrm{~m}^{3} /$ day.

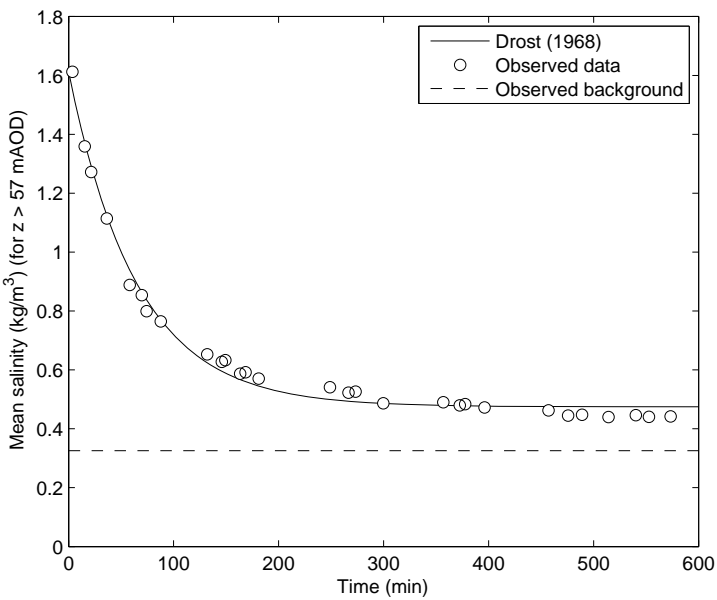

560 Figure 7 Plot of mean concentration against time in borehole PL10A for $\mathrm{z}>57 \mathrm{mAOD}$ under 561 ambient conditions. 


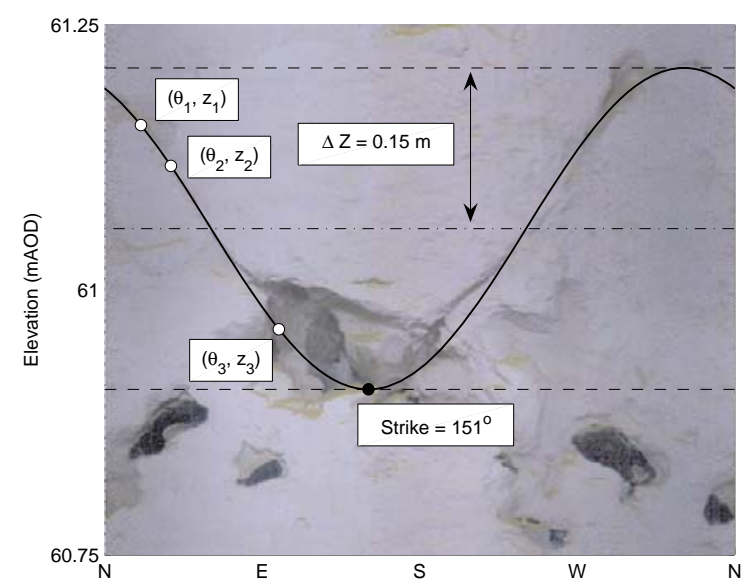

563 Figure 8 An example of a sine wave fit to a fracture in borehole PL10A. 